\title{
Evaluation of ink-jet printed current collecting grids and busbars for ITO-free organic solar cells
}

\author{
Yulia Galagan $^{\mathrm{a}, *}$, Erica W.C. Coenen ${ }^{\mathrm{b}}$, Sami Sabik ${ }^{\mathrm{a}}$, Harrie H. Gorter ${ }^{\mathrm{a}}$, Marco Barink ${ }^{\mathrm{b}}$, \\ Sjoerd C. Veenstra ${ }^{\mathrm{c}}$, Jan M. Kroon ${ }^{\mathrm{c}}$, Ronn Andriessen ${ }^{\mathrm{a}}$, Paul W.M. Blom ${ }^{\mathrm{a}}$ \\ ${ }^{a}$ Holst Centre, P.O. Box 8550, 5605 KN Eindhoven, The Netherlands \\ ${ }^{\mathrm{b}}$ TNO Technical Sciences, P.O. Box 6235, 5600 HE Eindhoven, The Netherlands \\ ${ }^{\mathrm{c}}$ Energy Research Centre of The Netherlands (ECN), P.O. Box 1, 1755 ZG Petten, The Netherlands
}

\section{A R T I C L E I N F O}

\section{Article history:}

Received 17 February 2012

Received in revised form

19 April 2012

Accepted 24 April 2012

\section{Keywords:}

Current collecting grids

Ink-jet printing

ITO-free solar cells

Polymer solar cells

Modeling

Electrical potential

\begin{abstract}
A B S T R A C T
ITO-free organic solar cells with ink-jet printed current collecting grids and high conducting PEDOT:PSS as a composite anode are demonstrated. Inkjet printed current collecting grids with different crosssectional areas have been investigated. The effect of the width and height of the grid lines and busbars has been measured and modeled by direct current (DC) simulations. The electrical potential in devices with different grid profiles have been calculated and reveal critical bottlenecks in the grid electrode geometry, as the ability of the busbar to collect all the current. Experimentally, the upper limit of the conductivity of the ink-jet printed current collecting grids is limited by the topology of the grids and shadow losses in the solar cells.
\end{abstract}

(c) 2012 Elsevier B.V. All rights reserved.

\section{Introduction}

Indium tin oxide (ITO) is commonly used as a transparent electrode in organic solar cells. However, the high price of indium in combination with the relatively low conductivity of ITO on flexible substrates $(60 \Omega / \mathrm{sq})$ creates a need for finding an alternative transparent electrode [1-5]. This alternative electrode should provide good conductivity, high transparency and relatively low price [6-8]. A promising candidate is the semiconducting material poly(3,4ethylenedioxythiophene)/poly(styrenesulfonate) (PEDOT:PSS) [9-13], which is highly transparent and can be easily produced from solution. However, the sheet resistance of high conductive PEDOT:PSS is typically in the range of $100-200 \Omega /$ sq, which is even higher with respect to the sheet resistance of ITO on flexible substrates. This high sheet resistance strongly decreases the maximum size of solar cells with only PEDOT:PSS as a transparent electrode. Aernouts at al. reported on the usage of PEDOT:PSS in combination with a metallic silver grid produced by a standard photographic technique [14]. The silver grid strongly increases the conductivity of the composite Ag-PEDOT:PSS electrode.

Alternative approaches for grid deposition are lithographic method [1,15,16], evaporation through a mask [17] or printing [1,18-24]. Recently, screen printed silver grids, with a sheet resistance

\footnotetext{
* Corresponding author. Tel.: +31 404020 447; fax: +31404020699.

E-mail address: yulia.galagan@tno.nl (Y. Galagan).
}

of $1 \Omega /$ sq, in combination with high conducting PEDOT:PSS have been reported as a good substitute for ITO electrodes in organic solar cells [18]. Screen printed current collecting grids can provide grid lines of typically $180 \mu \mathrm{m}$ wide and $1.5-2 \mu \mathrm{m}$ high. A problem is that over-coating of these relatively high grid lines with PEDOT:PSS and an active layer is very difficult, and devices are easily shorted. Such grids only can be used when they are embedded into substrate [18]. An interesting alternative for screen-printed metal grids is ink-jet printing. With ink-jet printing the amount of printed metal can be accurately controlled, and therefore, very thin lines with a typical resolution of 30-50 um can be printed. A complication of ink-jet printing is that increasing the height of the grid lines automatically leads to increased line widths, and therefore to enhanced shadow losses. In this study we systematically vary the width and height of ink-jet printed grids and the busbars. The role of busbars and effects of grid geometry and conductivity on the performance of $2 \times 2 \mathrm{~cm}^{2}$ organic bulkheterojunction solar cells are quantitatively evaluated.

\section{Experimental}

\subsection{ITO-based solar cells}

In this study $2 \times 2 \mathrm{~cm}^{2}$ ITO-based solar cells are being used as a reference to solar cells with a variety of ink-jet printed composite electrodes consisting of a silver grid in combination with high 


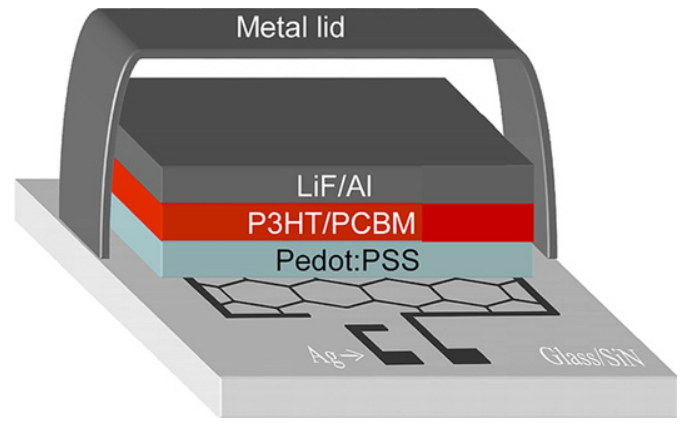

Fig. 1. Schematic illustration of the OPV device architecture.

conductive PEDOT:PSS. The ITO-based devices are prepared on both glass ( $0.7 \mathrm{~mm}$ thick) and barrier coated PEN substrates. The ITO is deposited by sputtering and subsequently patterned by photolithography. The ITO thickness was $120 \mathrm{~nm}$ with a sheet resistance of $13 \Omega /$ sq and $60 \Omega /$ sq for glass and foil substrates, respectively. Clevios P VP AI 4083 PEDOT:PSS from H.C. Starck was spin coated at $2000 \mathrm{rpm}$ on ITO substrates, resulting in a dry layer thickness of $60 \mathrm{~nm}$ after baking at $150{ }^{\circ} \mathrm{C}$ for $10 \mathrm{~min}$. The deposition of the photoactive layer and the metallic cathode are the same as for the ITO-free devices (see below).

\subsection{ITO-free organic solar cells}

The device architecture of the ITO-free solar cell is schematically shown in Fig. 1. The organic solar cell devices were prepared in an ambient atmosphere except for the cathode deposition, which is thermally evaporated under vacuum. The current collecting grids were ink-jet printed using a piezoelectric drop-on-demand system (Fujifilm Dimatix DMP-2800 16 nozzles). A silver nanoparticle based ink has been used (Suntronic U5603) in which the $\mathrm{Ag}$ nanoparticles (average diameter 30-50 $\mathrm{nm}$ ) are stabilized with poly(vinylpyrrolidone) (PVP) in ethylene glycol. Immediately after printing the current collecting grids are sintered in an oven at $130{ }^{\circ} \mathrm{C}$ for $30 \mathrm{~min}$. Highly conductive Orgacon TM PEDOT:PSS from Agfa-Gevaert was inkjet printed on top of the silver current collecting grids. For inkjet printing of PEDOT:PSS a Spectra Galaxy 256 print-head was used.

Poly(3-hexylthiophene) (P3HT) (Plextronics, Plexcore OS 2100) and $[6,6]-$ phenyl- $C_{61}$-butyric acid methyl ester (PCBM) (99\%, Solenne BV) were dissolved in 1,2-dichlorobenzene with a mixing ratio of $1: 1$ by weight. The solution was stirred for $3 \mathrm{~h}$ at $90^{\circ} \mathrm{C}$. The photoactive layer was spin coated using a $4 \mathrm{wt} \%$ blend at $1000 \mathrm{rpm}$ for $30 \mathrm{~s}$, which corresponds to a thickness of $220 \mathrm{~nm}$. The metal cathode ( $1 \mathrm{~nm} \mathrm{LiF,} 100 \mathrm{~nm} \mathrm{Al}$ ) was thermally evaporated in a vacuum chamber through a shadow mask. After cathode evaporation the samples were thermally annealed at $130{ }^{\circ} \mathrm{C}$ for $10 \mathrm{~min}$. The finished glass-based OPV devices were encapsulated with stainless steel lids using Huntsman Araldite ${ }^{\circledR}$ 2014-1 sealer. Flexible devices were encapsulated using a thin film barrier [25]. The current-voltage characteristics of the devices were measured using simulated AM 1.5 global solar irradiation $\left(100 \mathrm{~mW} / \mathrm{cm}^{2}\right)$ from a xenon-lamp-based solar simulator Oriel (LS0104) $150 \mathrm{~W}$. The conductivity of the grids is measured with a Keithley 2100 61/2 Digit. The layers thickness and the cross section areas of the printed grids were measured using a Veeco Dektak Profilometer.

\section{Results and discussion}

\subsection{Inkjet printing of current collecting grids}

Using inkjet printing, the current collecting grids are deposited by precise placement of picoliter volumes of liquid on the substrate.
Interaction between the printed material and substrate will affect the width of the line. Uniform droplets formation along the 16 nozzles of the printer, are performed by applying $10 \mathrm{kHz}$ frequency and a nozzle voltage of $24 \mathrm{~V}$. This delivers drops which contain around $10 \mathrm{pl}$ of ink, creating dot sizes of around $20 \mu \mathrm{m}$ in diameter.

The spreading behavior of the ink with inkjet printing depends on the surface energy of the substrate. The devices in this study were prepared on silicon nitride (SixNy) coated glass substrates or barrier coated PEN foil. Silicon nitride on the glass was used to simulate the surface properties of the flexible substrates, because silicon nitride is the top layer of the barrier coated flexible substrates. The relatively high surface energy of the SixNy coating $(55-60 \mathrm{mN} / \mathrm{m})$ limits the minimum attainable width of the printed lines. At the same time, the width of the printed lines depends on the drop spacing [26], which is set in inkjet printing parameters. In order to print continuous line patterns it is necessary to allow adjacent droplets to interact and coalesce. It is advantageous for these drops to interact while in a liquid state because surface tension forces will result in a smooth deposited surface. Tuning the spacing between each droplet allows reaching different height of the printed lines. After printing, the cross section area of the lines on 5 different places of the grid was measured. Fig. 2 illustrates typical cross-section profiles of the inkjet printed lines for different drop spacing on SixNy coated glass substrate. The maximum drop spacing which allows individual drops to coalesce for this ink and this substrate was $30 \mu \mathrm{m}$. With such drops spacing the minimum amount of silver ink is used. As a result, the printed lines are characterized by a minimum width and height that sets a higher limit for the resistance.

To obtain a higher conductivity of the current collecting grids, and to minimize series resistance losses, the grid requires a bigger amount of silver. Increasing the amount of metal in the current collecting grids has a positive effect in terms of conductivity.

The current collecting grid is the bottom layer in the device architecture and other functional layers are deposited on top of the grids. High topology of the grids prohibits a uniform deposition of the subsequent layers. As shown in Fig. 2 the width and the height of the grids cannot be changed independently, but simultaneously increase which creates additional shadow losses and has a negative effect on the $J_{\mathrm{sc}}$ in OPV devices. To find a balance between resistance, height and width of the current collecting grids, devices with different grids dimensions were prepared.

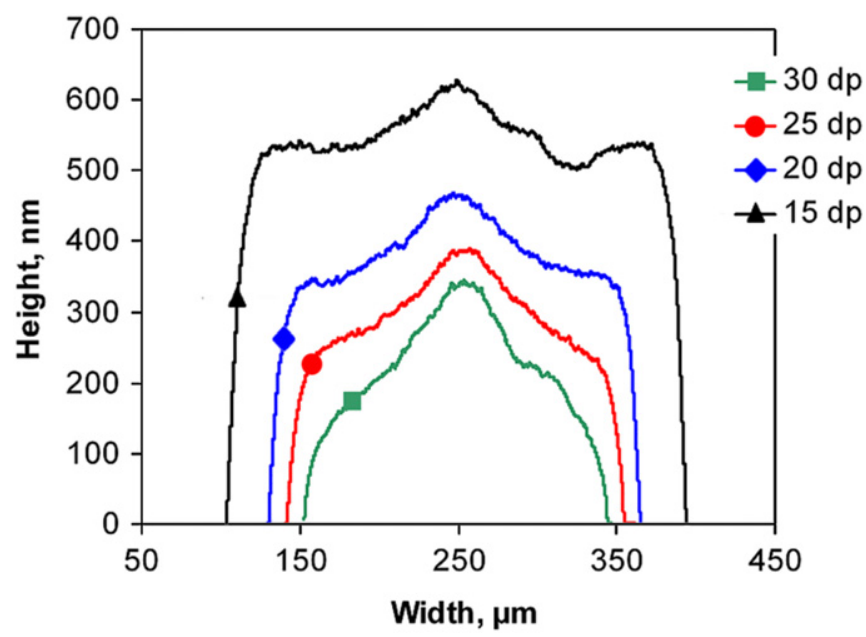

Fig. 2. Typical cross-section profiles of the ink-jet printed lines with set value of $100 \mu \mathrm{m}$ and different drop spacing (dp) on SixNy coated glass substrate. 


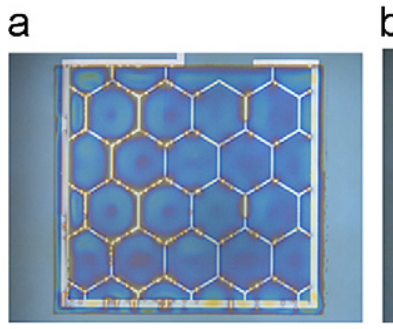

b

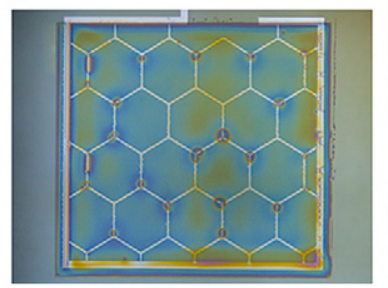

C

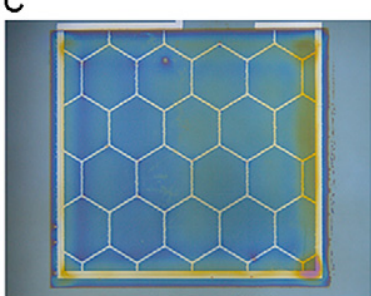

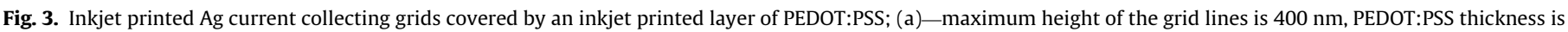

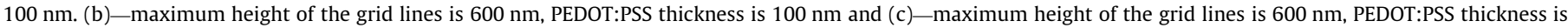
$200 \mathrm{~nm}$.

A $100 \mathrm{~nm}$ thick layer of high conducting PEDOT:PSS was inkjet printed on top of a hexagonally shaped grid with low profile (400 nm maximum height). Over-coating of such a grid by PEDOT:PSS typically is still well possible. Visually inspection with an optical microscope reveals good over-coating of such grids (Fig. 3a). However, increasing of the grids height beyond $400 \mathrm{~nm}$ introduces difficulties in the grids over-coating. Optical microscopic images reveal a lot of defects in the PEDOT:PSS layer that covers the current collecting grids with a higher profile (maximum height of $600 \mathrm{~nm}$ ) (Fig. 3b). These devices typically suffer from a significant current leakage due to short circuit. This problem can be partly solved by increasing the PEDOT:PSS layer thickness. A PEDOT:PSS layer with a thickness of $200 \mathrm{~nm}$ can cover the grids, except of intersect points, where the height of the grids is slightly bigger (Fig. 3c). However, increasing the PEDOT:PSS layer thickness has a negative effect on the transparency. It induces about 3\% loss in $J_{\text {sc. }}$. On the other hands, increasing of the PEDOT:PSS thickness is beneficial for the fill factor in OPV devices (Table 1, devices "3" and "4"). This is a result of lowering of the sheet resistance from $200 \Omega$ /sq to $100 \Omega$ /sq by doubling the PEDOT:PSS thickness to $200 \mathrm{~nm}$. The performance of the solar cells with different grids profile and different PEDOT:PSS thicknesses are summarized in Table 1 (devices "1"-“4").

From the results it is obvious that the current density in the devices strongly correlates with the grid surface coverage and the thickness of PEDOT:PSS layer. The $J_{\mathrm{sc}}$ decreases with increasing surface coverage as well as with increasing the thickness of PEDOT:PSS layer, because of a lower light transmittance. On the other hand increasing the PEDOT:PSS thickness also leads to slight increasing of fill factor. In total, devices with thicker and thinner PEDOT:PSS layers have the same efficiency, because these effects cancel each other.

From these experiments we find that a grid height of $600 \mathrm{~nm}$ is about the limit for successful devices manufacturing. A higher topology of the grids leads to a strongly enhanced current leakage and reduced efficiency due to short circuit in uncovered parts of the grid. The next question is whether ink-jet printed gridlines with a maximum height of $600 \mathrm{~nm}$ to allow over-coating are feasible in large-area solar cells. For this we combine a systematic series of experiments on $2 \times 2 \mathrm{~cm}^{2}$ ITO-free organic solar cells with theoretical modeling of the resistive losses.

\subsection{Theoretical modeling}

In order to quantify the influence of the current-collecting grids geometry on the overall performance of organic solar cells, direct current (DC) simulations have been performed. The multiphysics finite element package COMSOL has been used to obtain the electrical potential field $V$ by solving Poisson's equation for conductive media

$\nabla(\sigma \nabla V)=0$
The electrode considered consists of two materials: PEDOT:PSS and an inkjet printed sintered silver ink with electrical conductivities $(\sigma)$ of $2 \times 10^{4} \mathrm{~S} / \mathrm{m}$ and $4.2 \times 10^{6} \mathrm{~S} / \mathrm{m}$, respectively. The layout of the anode consisting of the current-collecting grid and PEDOT:PSS is shown in Fig. 4a. The gray area represents the PEDOT:PSS. The grid-lines have cross sections as shown in Fig. 2. Because ink-jet printed grids have a non-rectangular profile, for calculation the average lines height was taken (see Table 1). The busbar had a varied width (700 $\mu \mathrm{m}$ and $2000 \mu \mathrm{m})$ and height of $450 \mathrm{~nm}$.

Fig. 4b shows the current density as a function of the applied voltage for a P3HT:PCBM solar cell. This JV curve has been recorded for a very small solar cell (glass/ITO/Pedot/OPV/LiF/Al). As the size of this reference cell is very small $\left(0.09 \mathrm{~cm}^{2}\right)$, the potential field is homogeneous over the full layout of the cell and this recorded curve is used as an input parameter for the modeling of the larger cell depicted in Fig. 4a.

An electrical potential is prescribed on the edge of the busbar, which is referred to as the work voltage, $V_{\text {work. }}$ In case of an open busbar, meaning that the busbar is interrupted between $\mathrm{A}$ and $\mathrm{B}$ (Fig. 4a) the $V_{\text {work }}$ is imposed on edge A. For a closed busbar $V_{\text {work }}$ is imposed on both edges A and B. Electric fluxes through the remaining exterior boundaries are set to be zero, i.e. these boundaries are electrically insulated. The electric potential is assumed to be continuous across all internal boundaries in the composite electrode.

Based on the current density-potential relation depicted in Fig. $4 \mathrm{~b}$, the total current through the device can be calculated at the converged state for the electrical potential field. The total current through the cell is obtained as the integral of the current density $J_{\mathrm{P}}$ over the PEDOT:PSS surface $A_{\mathrm{P}}$. The effective current density $J_{\text {cell }}$ is defined as the total current divided by the cell, that is

$J_{\text {cell }}=\frac{1}{A_{\text {cell }}} \int_{A_{\mathrm{P}}} J_{\mathrm{P}} d A_{\mathrm{P}}$

The calculations were performed for the $2 \times 2 \mathrm{~cm}^{2}$ solar cells with (1) different thicknesses (different effective conduction capacities) of current collecting grids, (2) different widths of the current collecting busbar, and (3) busbar with open and closed loops. The efficiency parameters of the modeled solar cells are shown in Table 1, and selected cases are depicted in Fig. 5 and compared with experimental results. Theoretical calculations show a good match with experimental results. The lower values of $J_{\mathrm{sc}}$ in experimental devices can be attributed to the use of SixNy-coated glass substrates, which decreases the light transmittance into the devices.

Increasing the dimensions of the gridlines (see devices " 1 ", "2" and "3", "4", Table 1) has reduced the surface resistance more than 2 times, from 11.6 to $4.8 \Omega / \mathrm{sq}$ (see Table 1 ). As a result the thick grid-lines have a cross sectional area and thus effective conduction capacity which is 2.4 times larger with respect to the thin grid lines. The grids surface coverage, however, increases 


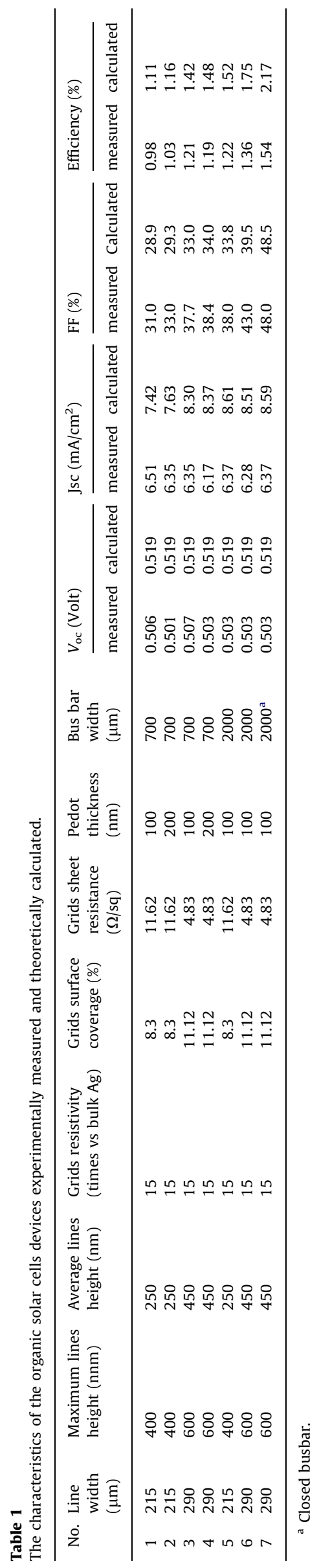

from $8.3 \%$ to $11.12 \%$. Fig. 5 shows that this tradeoff is in favor of increasing the cross sectional area (devices " 1 " $\rightarrow$ devices " 3 "). However, a big increase of the fill factor by decreasing the grid resistance was not observed as expected from the modeling. The fill factor has increased by only $5-7 \%$. This suggests that there are other parameters which limit current collection in the devices. To understand this better the devices were studied with infra-red lock-in thermography with the Thermosensorik CMT 384SM camera. Lock-in settings are 132 frames/period $1.002 \mathrm{~Hz}$. The infrared image of device "3" (600 nm high grids and $100 \mathrm{~nm}$ PEDOT:PSS layer) is shown in Fig. 6a, the corresponding photograph of the device is shown in Fig. 6c.

Visualization of the heat or energy dissipation in the devices clearly illustrates that there is an area with very high current leakage close to the anode contact point. In the devices "1"-" 4 ", a $700 \mu \mathrm{m}$ wide and $450 \mathrm{~nm}$ high (average height) busbar was used, with a resistance of $64.2 \Omega$ (calculated value). Calculations show that current collecting busbar can be the limiting factor in the device design. If the resistance of the busbar is too high, the busbar is not able to collect all the current generated in the solar cell, leading to a high current leakage. According to the modeling decreasing the resistance of the busbar from 64.2 to $22.5 \Omega$ should significantly increase the fill factor of the devices. Indeed, devices with a $2000 \mu \mathrm{m}$ wide busbar (Fig. 5) have significantly improved fill factor (devices "5" and "6" in Table 1). For example, devices with identical current collecting grids, but different busbars, have efficiencies raising from $0.98 \%$ to $1.22 \%$ (for thin current collecting grids, devices "1" $\rightarrow$ " 5 ") and from $1.21 \%$ to $1.36 \%$ (for thick current collecting grids, devices " 3 " $\rightarrow$ " 6 ") with increasing busbar width from $700 \mu \mathrm{m}$ to $2000 \mu \mathrm{m}$ (Fig. 5). The efficiency increase is achieved mainly due to an increase of the fill factor. The thermography image of the device with a wider busbar (Fig. 6b) shows that the problem of current leakage is solved (a photographic image of the device is shown in Fig. 6d).

Interestingly, modeling shows that the largest gain in performance is achieved by "closing' the busbar (" 6 " $\rightarrow$ "7") as a result of imposing the work voltage $V_{\text {work }}$ on both ends of the busbar. These numerically obtained results are in good agreement with the experimental observations. The results illustrate very big difference in the device performances for the devices with open (device "6") and closed busbars (devices "7" in Table 1 and Fig. 5).

In Fig. 7, the device geometry and the electrical potential field are depicted for the four different inkjet printed current collecting grids geometries, each at its work voltage of maximal power, i.e. maximum $J_{\text {cell }} \times V_{\text {work }}$. Increasing the grid line width (" 1 " $\rightarrow$ " 3 ") has relatively small contribution in achieving a uniform potential field, compared to decreasing the resistance of the busbar (" 3 " $\rightarrow$ " 6 "). This confirms that for this particular design the capacity of the busbar is the limiting component. A closed busbar ("7") results in a significant performance improvement without increasing the amount of grid material. Thus, increasing the height and the width of current collecting grids, increasing the width of busbar, and the usage of busbar with closed connection gives possibility to increase efficiency from $0.98 \%$ to $1.54 \%$, the fill factor increases from $31 \%$ to $48 \%$.

\subsection{Discussion}

The highest value of PCE for ITO-free solar cells with inkjet printed current collecting grids in this study was $1.54 \%$ (devices " 7 "), which is significantly higher as compared to devices only made with PEDOT:PSS as transparent electrode (Fig. 8, Table 2, devices "8"). However, it is still a bit lower than the PCE of the ITO-based reference device made on glass with an ITO sheet resistance of $13 \Omega /$ sq (device "9"). The inkjet printed current-collecting grids used here have approximately the same sheet resistance (5-12 $\Omega /$ sq, see 
a

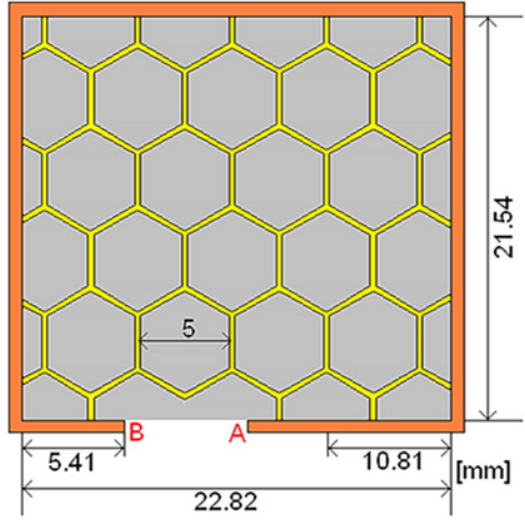

b

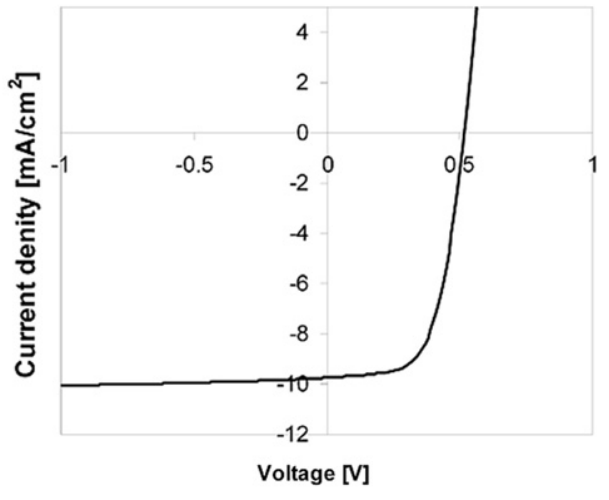

Fig. 4. (a)-Layout of the anode in the OPV-cell and (b) - JV curve of the $3 \times 3 \mathrm{~cm}^{2}$ P3HT/PCBM cell on ITO used as input parameter for the modeling.
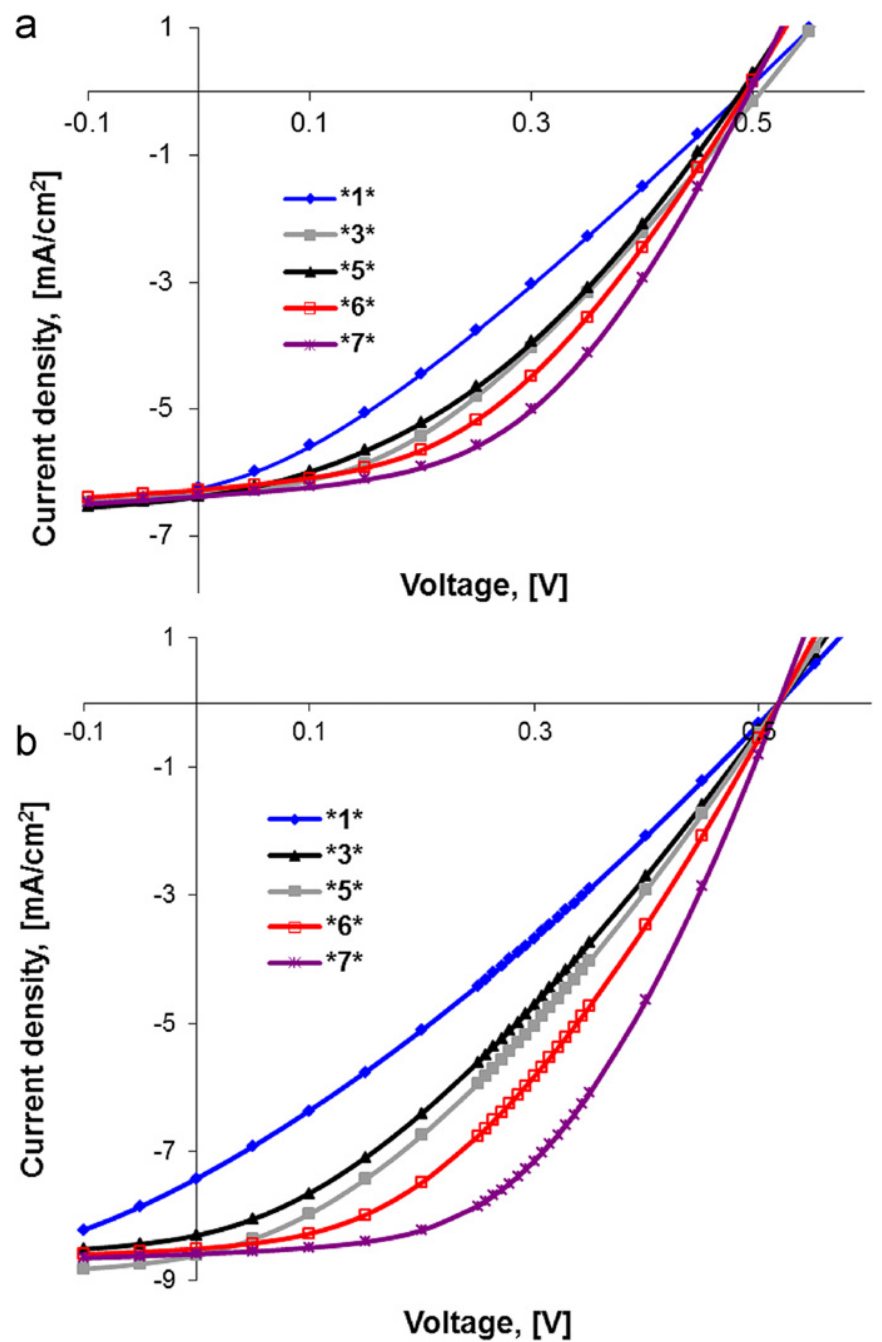

Fig. 5. $J V$ curves of the devices with inkjet printed current collecting grids (a) experimentally measured and (b) theoretically calculated (for devices description, see Table 1).

Table 1) as ITO on glass, however, it should be taken into account that these values are provided by grids, which cover $10-12 \%$ of the surface.

Switching from glass to flexible substrates significantly decrease the efficiency of ITO-based devices (device "10", Fig. 8). Increasing
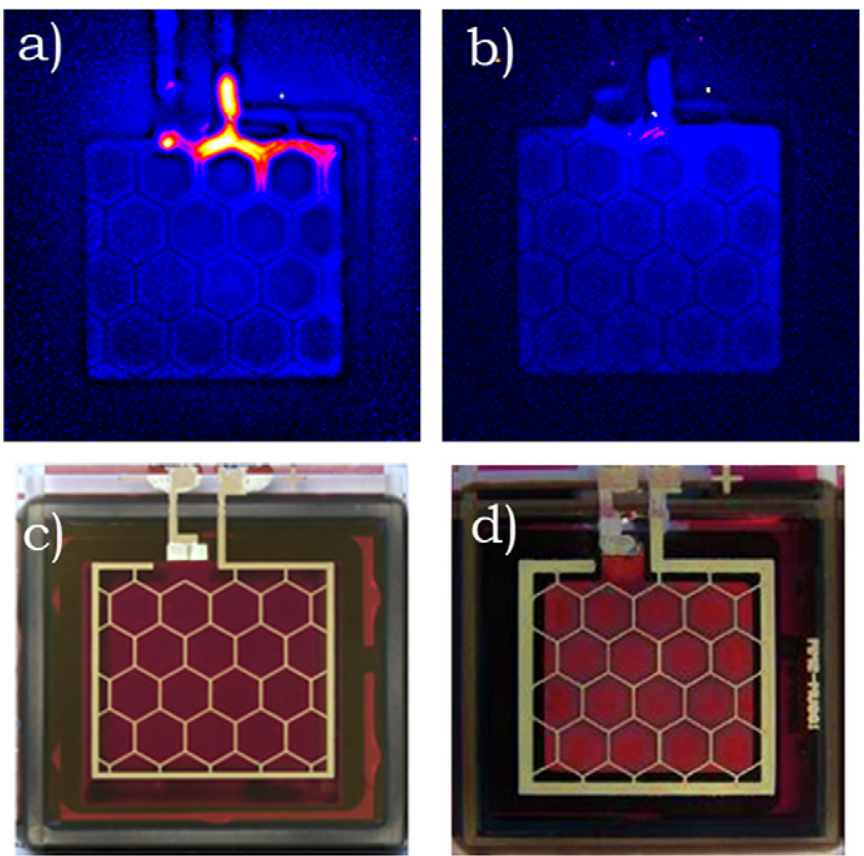

Fig. 6. Infra-red lock in thermography images of (a) - devices "3" (maximum height of the grids is $600 \mathrm{~nm}$, PEDOT:PSS thickness is $100 \mathrm{~nm}$, busbar width is $700 \mu \mathrm{m}$ ) and (b) — devices " 6 " (maximum height of the grids is $600 \mathrm{~nm}$, PEDOT:PSS thickness is $100 \mathrm{~nm}$ and busbar width is $2000 \mu \mathrm{m}$ ); Photographic images of the devices: (c)—device " 3 " and (d)—device " 6 ".

the sheet resistance of ITO from $13 \Omega /$ sq (ITO/glass) to $60 \Omega / \mathrm{sq}$ (ITO/foil) for $2 \times 2 \mathrm{~cm}^{2}$ solar cells reduces the efficiency more than twice (Table 2). The fill factor drops down from $52.3 \%$ to $29.6 \%$. For ITO-free devices with a metal grid the performance on glass and plastic substrates is nearly the same (devices "11"). Slightly lower current is observed, due to the difference in transparency of the flexible and glass substrates. However, the fill factor remains the same. This illustrates an advantage of a composite electrode over the standard ITO electrode for flexible substrates.

A further improvement of ITO-free device performance would be possible by further increasing of the amount of metal in the current collecting grids. However, as shown in Fig. 2 an increasing amount of metal in ink-jet printed current collecting grids will automatically increase the height of the grids. Furthermore, the yield of OPV devices with printed current collecting grids higher the $600 \mathrm{um}$ is very low. The only way to overcome this problem is 

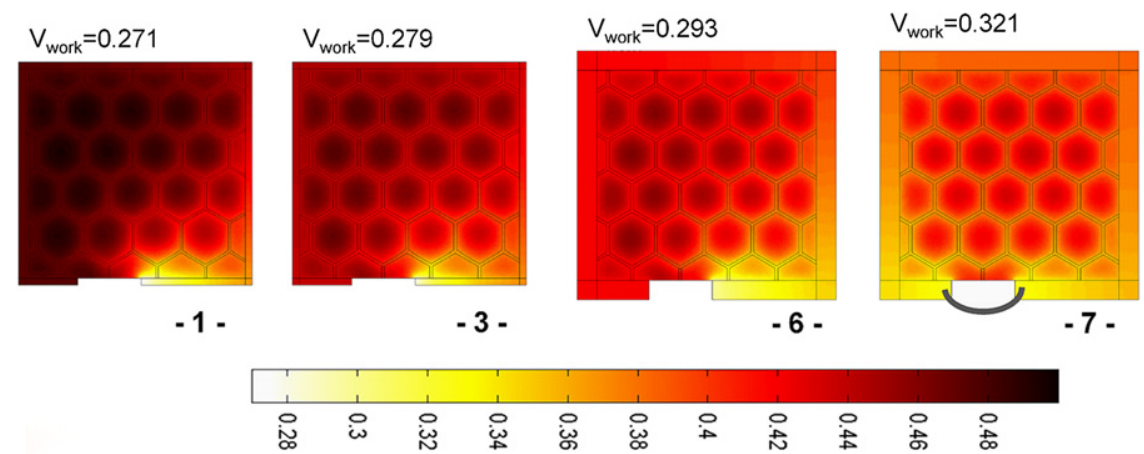

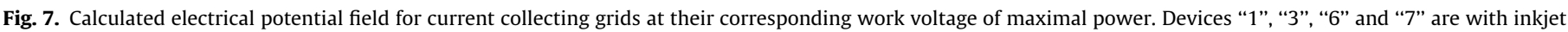
printed current collecting grids (see Table 1).

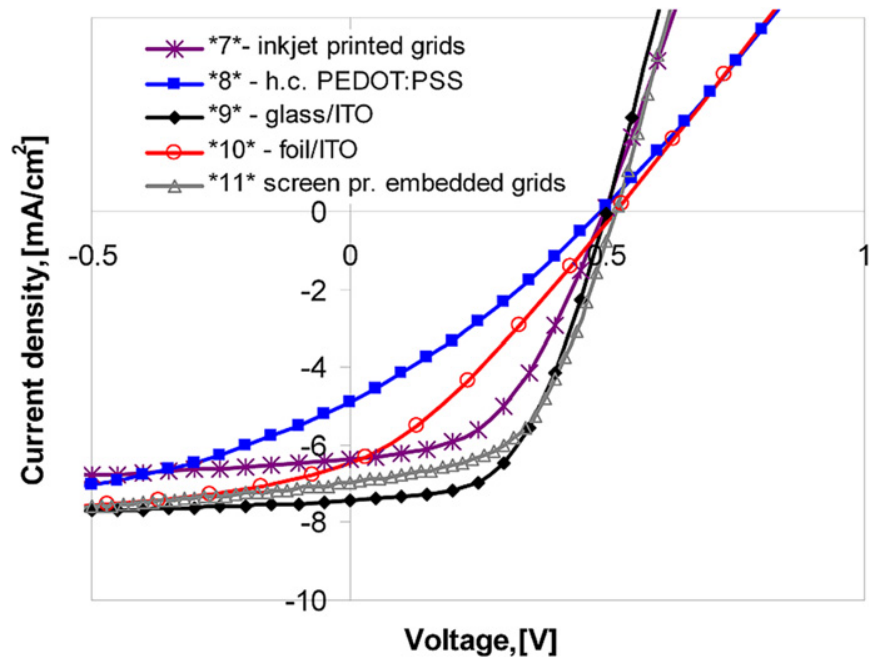

Fig. 8. $J V$ curves of the $2 \times 2 \mathrm{~cm}^{2}$ devices with ITO, PEDOT:PSS and Ag-grid/ PEDOT:PSS electrodes (for devices description, see Table 2).

Table 2

The characteristics of the organic solar cells devices.

\begin{tabular}{lllllll}
\hline No. $\begin{array}{l}\text { Substrate/ } \\
\text { Anode }\end{array}$ & $\begin{array}{l}\text { Anode sheet } \\
\text { resistance } \\
(\text { Ohm/sq) }\end{array}$ & $\begin{array}{l}V_{\text {oc }} \\
(\text { Volt })\end{array}$ & $\begin{array}{l}J_{\text {sc }} \\
\left(\mathrm{mA} / \mathrm{cm}^{2}\right)\end{array}$ & $\begin{array}{l}F F \\
(\%)\end{array}$ & $\begin{array}{l}\text { Efficiency } \\
(\%)\end{array}$ \\
\hline 7 & $\begin{array}{l}\text { glass/inkjet } \\
\text { pr.Ag/h.c.Pedot } \\
\text { glass/h.c. }\end{array}$ & $4.83 / 500$ & 0.503 & 6.37 & 48.0 & 1.54 \\
\hline $\begin{array}{l}\text { Pedot } \\
\text { glass/ITO }\end{array}$ & 1300 & 0.490 & 4.86 & 29.6 & 0.71 \\
10 & $\begin{array}{l}\text { foil/ITO } \\
\text { foil/inkjet } \\
\text { pr.Ag/h.c.Pedot } \\
\text { foil/screen } \\
\text { pr.embed. }\end{array}$ & $\begin{array}{l}1 / 50 \\
\text { Ag/h.c.Pedot }\end{array}$ & 0.501 & 7.44 & 52.3 & 1.99 \\
& & 0.489 & 6.59 & 29.6 & 0.95 \\
& & 0.502 & 6.15 & 48.0 & 1.48 \\
\hline
\end{tabular}

to embed the grid lines into the substrate. Recently, an approach was demonstrated where $2 \mu \mathrm{m}$ high screen printed gridlines with a sheet resistance of $1 \Omega / \mathrm{sq}$ were embedded into the substrate [18]. Applying this method here to ITO-free devices with screen printed embedded current collecting grids leads to a further improvement of the efficiency of the ITO-free cell from $1.54 \%$ towards $1.92 \%$ (Table 2 , devices "12"). The $J-V$ characteristic of this device is shown in Fig. 8. The fill factor amounts to 52\%, which is even higher than for the same size devices with ITO electrode, both on foil and glass substrates. However, the $J_{s c}$ of the devices with embedded current collecting grids is lower than for glass-ITO device. This can be explained by the transparency of the glass and barrier coated PEN foil used as substrates (transparency of such substrate is only $85 \%$ compared with glass substrate) and by shadowing effect provided by grids $(7.1 \%)$.

\section{Conclusions}

In conclusion, we have analyzed the effect of the height and width of ink jet printed grid lines and busbars on the performance of P3HT:PCBM solar cells. Increasing the height leads to a simultaneous increase of the width of the grid-lines, which enhances shadowing effects. Grid heights larger than $600 \mathrm{~nm}$ limit the possibility for over-coating by PEDOT:PSS and the active layer. Further increase of the grid height and conductivity is possible by embedding the current collecting grids into the substrate.

\section{Acknowledgments}

This work has been supported in part by the European Commission as part of the Framework 7 ICT 2009 collaborative project HIFLEX (Grant Agreement number 248678) and by the Dutch ministry of economic affairs of the Netherlands.

\section{References}

[1] Y. Galagan, B. Zimmermann, E.W.C. Coenen, M. Jørgensen, D.M. Tanenbaum, F.C. Krebs, H. Gorter, S. Sabik, L.H. Slooff, S.C. Veenstra, J.M. Kroon, R. Andriessen, Organic solar cells: current collecting grids for ITO-free solar cells, Advanced Energy Materials 2 (2012) 103-108.

[2] A.J. Medford, M.R. Lilliedal, M. Jørgensen, D. Aarø, H. Pakalski, J. Fyenbo, F.C. Krebs, Grid-connected polymer solar panels: initial considerations of cost, lifetime, and practicality, Optics Express 18 (19) (2010) A272-A285.

[3] F.C. Krebs, All solution roll-to-roll processed polymer solar cells free from indium-tin-oxide and vacuum coating steps, Organic Electronics 10 (2009) 761-768.

[4] F.C. Krebs, Roll-to-roll fabrication of monolithic large-area polymer solar cells free from indium-tin-oxide, Solar Energy Materials and Solar Cells 93 (2009) 1636-1641.

[5] R. Po, C. Carbonera, A. Bernardi, F. Tinti, N. Camaioni, Polymer- and carbonbased electrodes for polymer solar cells: toward low-cost, continuous fabrication over large area, Solar Energy Materials and Solar Cells 100 (2012) 97-114.

[6] N. Espinosa, R. García-Valverde, A. Urbina, F.C. Krebs, A life cycle analysis of polymer solar cell modules prepared using roll-to-roll methods under ambient conditions, Solar Energy Materials and Solar Cells 95 (2011) 1293-1302.

[7] N. Espinosa, R. García-Valverde, F.C. Krebs, Life-cycle analysis of product integrated polymer solar cells, Energy and Environmental Science 4 (2011) 1547-1557.

[8] N. Espinosa, R. García-Valverde, A. Urbina, F. Lenzmann, M. Manceau, D. Angmo, F.C. Krebs, Life cycle assessment of ITO-free flexible polymer solar 
cells prepared by roll-to-roll coating and printing, Solar Energy Materials and Solar Cells 97 (2012) 3-13.

[9] Y. Zhou, F. Li, S. Barrau, W. Tian, O. Inganäs, F. Zhang, Inverted and transparent polymer solar cells prepared with vacuum-free processing, Solar Energy Materials and Solar Cells 93 (2009) 497-500.

[10] Y. Zhou, H. Cheun, S. Choi, J.W.J. Potscavage, C. Fuentes-Hernandez, B. Kippelen, Indium tin oxide-free and metal-free semitransparent organic solar cells, Applied Physics Letters 97 (2010) 153304.

[11] S.K. Hau, H.-L. Yip, J. Zou, A.K.Y. Jen, Indium tin oxide-free semi-transparent inverted polymer solar cells using conducting polymer as both bottom and top electrodes, Organic Electronics 10 (2009) 1401-1407.

[12] E. Ahlswede, W. Muhleisen, M.W. Bin Moh Wahi, J. Hanisch, M. Powalla, Highly efficient organic solar cells with printable low-cost transparent contacts, Applied Physics Letters 92 (2008) 143307.

[13] Y.-M. Chang, L. Wang, W.-F. Su, Polymer solar cells with poly(3,4-ethylenedioxythiophene) as transparent anode, Organic Electronics 9 (2008) 968-973.

[14] T. Aernouts, P. Vanlaeke, W. Geens, J. Poortmans, P. Heremans, S. Borghs, R. Mertens, R. Andriessen, L. Leenders, Printable anodes for flexible organic solar cell modules, Thin Solid Films 451-452 (2004) 22-25.

[15] K. Tvingstedt, O. Inganäs, Electrode grids for ITO-free organic photovoltaic devices, Advanced Materials 19 (2007) 2893-2897.

[16] J. Zou, H.-L. Yip, S.K. Hau, A.K.Y. Jen, Metal grid/conducting polymer hybrid transparent electrode for inverted polymer solar cells, Applied Physics Letters 96 (2010) 203301-203303.

[17] M. Glatthaar, M. Niggemann, B. Zimmermann, P. Lewer, M. Riede, A. Hinsch, J. Luther, Organic solar cells using inverted layer sequence, Thin Solid Films 491 (2005) 298-300.
[18] Y. Galagan, J.E. Rubingh, R. Andriessen, C.C. Fan, P. Blom, S.C. Veenstra J.M. Kroon, ITO-free flexible organic solar cells with printed current collecting grids, Solar Energy Materials and Solar Cells 95 (2011) 1339-1343.

[19] Y. Galagan, R. Andriessen, E. Rubingh, N. Grossiord, P. Blom, S. Veenstra, W Verhees, J. Kroon, Toward fully printed organic photovoltaics: processing and stability, presented at Lope-C, Frankfurt, Germany, 2010, pp. 88-91.

[20] R. Søndergaard, M. Hösel, D. Angmo, T.T. Larsen-Olsen, F.C. Krebs, Roll-to-roll fabrication of polymer solar cells, Materials Today 15 (2012) 36-49.

[21] F.C. Krebs, J. Fyenbo, D.M. Tanenbaum, S.A. Gevorgyan, R. Andriessen, B. van Remoortere, Y. Galagan, M. Jørgensen, The OE-A OPV demonstrator anno domini 2011, Energy and Environmental Science 4 (2011) 4116-4123.

[22] F.C. Krebs, Fabrication and processing of polymer solar cells: a review of printing and coating techniques, Solar Energy Materials and Solar Cells 93 (2009) 394-412.

[23] F.C. Krebs, R. Søndergaard, M. Jørgensen, Printed metal back electrodes for R2R fabricated polymer solar cells studied using the LBIC technique, Solar Energy Materials and Solar Cells 95 (2011) 1348-1353.

[24] F.C. Krebs, J. Fyenbo, M. Jørgensen, Product integration of compact roll-to-roll processed polymer solar cell modules: methods and manufacture using flexographic printing, slot-die coating and rotary screen printing, Journal of Materials Chemistry 20 (2010) 8994-9001.

[25] F. van Assche, H. Rooms, E. Young, J. Michels, T. van Mol, G. Rietjens, P. van de Weijer, P. Bouten, AIMCAL Fall Technical Conference and 22nd International Vacuum Web Coating Conference, 2008.

[26] D. Soltman, V. Subramanian, Inkjet-printed line morphologies and temperature control of the coffee ring effect, Langmuir 24 (2008) 2224-2231. 